\title{
PENGARUH PENDIDIKAN KESEHATAN DENGAN MEDIA AUDIO VISUAL TERHADAP PENGETAHUAN REMAJA PUTRI TENTANG PEMERIKSAAN PAYUDARA SENDIRI (SADARI)
}

\section{THE INFLUENCE OF HEALTH EDUCATION WITH AUDIO VISUAL MEDIA TO THE KNOWLEDGE OF TEENAGE GIRLS ABOUT BREAST SELF- EXAMINATION (BSE)}

\author{
${ }^{1}$ R. Tri Rahyuning Lestari ${ }^{2},{ }^{2}$ i Gusti Ayu Satya Laksmi ${ }^{2},{ }^{3}$ Silvia Ni Nyoman Sintari ${ }^{3}$.
} STIKes Wira Medika Bali

\begin{abstract}
ABSTRAK
Kanker payudara merupakan penyakit dengan angka kejadian yang cukup tinggi di berbagai negara dan memiliki resiko kematian yang tinggi jika ditangani secara terlambat. Pemeriksaan payudara sendiri (SADARI) dapat dilakukan untuk mendeteksi gejala kanker payudara secara dini sehingga dapat mengurangi resiko kematian. Penelitian ini bertujuan untuk mengetahui adanya pengaruh pendidikan kesehatan dengan media audio visual terhadap pengetahuan remaja putri tentang pemeriksaan payudara sendiri (SADARI) di SMAN 1 Kuta Utara.Metode penelitian ini menggunakan pre eksperimental dengan one group pre-post test design. Sampel pada penelitian ini berjumlah 33 siswi yang dipilih menggunakan teknik purposive sampling. Pengukuran pengetahuan siswi dalam pre test didapatkan hasil 17 orang (51,5\%) berpengetahuan kurang dan 16 orang (48,5\%) bepengetahuan cukup. Pada hasil post test pengetahuan didapatkan peningkatan yaitu 20 orang $(60,6 \%)$ berpengetahuan baik dan 13 orang $(39,4 \%)$ berpengetahuan cukup. Hal ini disebabkan karena siswi telah mendapatkan perlakuan berupa penyampaian informasi melalui pendidikan kesehatan dengan media audio visual tentang SADARI yang telah diberikan oleh peneliti.
\end{abstract}

Kata kunci : Pendidikan Kesehatan, Pengetahuan, SADARI

\begin{abstract}
ABSTRACK
Breast Cancer is a desease with high incidence rate in many countries and has high risk of dead if it handled late. Breast Self-Examination (BSE) can be performed to detect breast cancer symptoms early so it can reduce the risk of death. The goal of the research is to know more about the the influence of health education with audio visual media to the knowledge of teenage girls about breast self-examination (BSE) in SMAN 1 Kuta Utara. The method of this research is pre experimental design with one group pre-post test design. The sample of this research is 33 students selected using purposive sampling technique. The measurement of student's knowledge in pre test is 17 person $(51,5 \%)$ have a less knowledge and 16 person (48,5\%) have an enough knowledge. The post test result is 20 person $(60,6 \%)$ have a good knowledge and 13 person $(39,4 \%)$ have an enough knowledge.
\end{abstract}


This is because of the sutend have already get the intervention form of give the information through the health education with audio visual media about BSE.

Keywords : Health Education, Knowledge, BSE

Alamat Korespondensi $\quad$ : Perumahan Griya Loka N0.22 Subak Dalem Denpasar

Email : trilestari100@gmail.com

\section{PENDAHULUAN}

Remaja adalah individu yang berusia antara 11-21 tahun, ditandai oleh perubahan pada penampilan fisik dan fungsi fisiologis, terutama yang terkait dengan kelenjar seksual dan masa dimana individu mengalami perubahanperubahan dalam aspek kognitif, emosi, sosial, dan moral di antara masa kanakkanak menuju masa dewasa (Kusmiran, 2014). Pada era globalisasi ini remaja Indonesia sedang mengalami perubahan sosial yang cepat dari masyarakat tradisional menuju masyarakat modern, yang juga mengubah norma-norma, nilainilai, dan gaya hidup mereka. Hal tersebut mengakibatkan kerentanan remaja terhadap berbagai macam penyakit (Agustiani, 2009). Banyaknya polutan juga ikut meningkatkan risiko gangguan kesehatan bagi remaja (Artanty, 2011). Banyak risiko gangguan kesehatan yang mampu menyerang remaja saat ini, namun perubahan gaya hidup, norma-norma dan nilai-nilai akan sangat berpengaruh pada kesehatan reproduksi seorang remaja (Marmi, 2014).

Terdapat berbagai macam penyakit reproduksi yang dapat menyerang seorang remaja pada saat ini maupun saat remaja tersebut beranjak menjadi dewasa.Salah satu penyakit sistem reproduksi yang memiliki angka kejadian cukup tinggi adalah kanker payudara. Menurut WHO (2013) dalam 8-9\% wanita akan mengalami kanker payudara. Selain itu menurut NCI (National Cancer Institute) (2013) terdapat perkiraan kasus baru 232.340 wanita sedangkan kasus kematian akibat kanker payudara sejumlah 39.620 wanita. Situs resmi American Cancer Society (2016) mengemukakan bahwa kanker payudara termasuk jenis kanker kedua yang paling mematikan setelah kanker paru-paru. Angka kanker payudara di Indonesia sendiri berdasarkan Sistem Informasi Rumah Sakit (SIRS) tahun 2014, jumlah pasien rawat jalan maupun rawat inap yang mengidap kanker payudara berjumlah 12.014 orang $(28,7 \%)$ dan kanker leher rahim berjumlah 5.349 orang $(12,8 \%)$.

Menurut data IARC (International Agency for Research on Cancer) tahun 2012 dalam Kemenkes RI 2015, diketahui bahwa kanker payudara merupakan penyakit kanker dengan presentase kasus baru tertinggi, yaitu sebesar 43,3\%, dan presentase kematian akibat kanker payudara sebesar 12,9\%. Berdasarkan data Riset Kesehatan Dasar tahun 2013, estimasi jumlah kanker payudara di Indonesia mencapai $0,5 \%$ per 1000 perempuan atau 61.682 perempuan. Provinsi Bali sendiri memiliki estimasi jumlah penderita kanker payudara mencapai $0,6 \%$ per 1000 perempuan atau 1.233 perempuan (Kemenkes RI, 2015). Menurut Yayasan Kanker Indonesia (YKI) (2015) pada lima tahun terakhir kanker payudara terus meningkat. Dari keseluruhan total penderita kanker payudara, 40\% penderita berobat pada stadium awal, 30\% pada stadium lanjut, dan 30\% dengan metastasis. Ketua Yayasan Kanker Payudara Indonesia (YKPI) Linda Gumelar (dalam Antara News, 
2015) mengatakan bahwa di Indonesia sendiri kanker payudara menjadi kasus kematian tertinggi dengan angka $21,5 \%$ per 100.000 perempuan dan yang menjadi salah satu alasan tingginya angka kematian tersebut adalah akibat keterlambatan penderita melakukan pemeriksaan ke pelayanan kesehatan.

Salah satu cara yang dapat dilakukan untuk mengurangi angka kematian tersebut adalah dengan melakukan deteksi dini kanker payudara yang salah satunya adalah pemeriksaan payudara sendiri (SADARI). Pemeriksaan payudara sendiri (SADARI) adalah sebuah tindakan pengembangan kepedulian seorang wanita terhadap kondisi payudaranya sendiri (Artanty, 2011). Meningkatkan pengetahuan remaja tentang sadari sedini mungkin dapat membawa pengaruh baik bagi remaja hingga menjadi wanita dewasa nanti. Salah satu upaya yang dapat dilakukan untuk meningkatkan pengetahuan remaja dalam melakukan sadari adalah dengan memberikan pendidikan kesehatan.

Pendidikan kesehatan adalah proses perubahan perilaku yang dinamis, dimana perubahan tersebut bukan hanya sekedar transfer materi atau teori dari seorang ke orang yang lain dan bukan juga seerangkat prosedur, akan tetapi perubahan terjadi karena adanya kesadaran dari dalam diri individu, kelompok, atau masyarakat (Wahit, 2012). Dalam menyampaikan pendidikan kesehatan terdapat media atau alat bantu guna mempermudah penyampaian informasi kesehatan. Salah satu jenis media pendidikan adalah media audio visual (Notoatmodjo, 2012). Menurut Ahmad Kholid (2012), media audiovisual adalah media yang mempunyai unsur suara dan unsur gambar, cara menghasilkan dan menyampaikan materi dengan menggunakan mesin-mesin mekanis dan elektronik untuk menyjikan pesanpesan audio dan visual. Berdasarkan studi pendahuluan yang dilakukan di SMAN 1 Kuta Utara menyatakan bahwa jumlah siswi kelas X sebanyak 252 siswi dan seluruhnya belum pernah mendapatkan pendidikan kesehatan terkait deteksi dini kanker payudara. Wawancara singkat juga dilakukan dengan 10 orang siswi, dan mendapatkan data bahwa 8 dari 10 siswi tidak mengetahui bagaimana melakukan sadari dan 2 orang mengetahui tentang sadari tapi tidak mampu menjelaskan dengan spesifik. Berdasarkan permasalahan di atas peneliti tertarik untuk meneliti tentang "Pengaruh Pendidikan Kesehatan dengan Media Audio Visual terhadap Pengetahuan Remaja Putri Tentang Pemeriksaan Payudara Sendiri (SADARI)".

\section{METODE PENELITIAN}

Dalam penelitian ini desain yang digunakan adalah Pre Eksperimental dengan One Group Pre-Post Test Desain. Rancangan ini memiliki ciri yaitu mengungkapkan hubungan sebab akibat dengan cara melibatkan satu kelompok subjek, yang mana kelompok subjek tersebut akan diobservasi sebelum dilakukan intervensi, kemudian diobservasi lagi setelah intervensi. Penelitian ini dilakukan di SMAN 1 Kuta Utara. Waktu penelitian dilakukan pada bulan Mei 2018.

Populasi pada penelitian ini adalah 252 orang. Penelitian ini menggunakan teknik purposive sampling yang didasarkan pada pertimbangan yang dibuat oleh peneliti. Jumlah sampel yang ditentukan dalam penelitian ini adalah 30 orang dan ditambah dengan drop out menjadi 33 orang. Pemilihan responden didasarkan pada kriteria inklusi dan eksklusi yang telah ditentukan oleh peneliti. Variabel bebas dalam penelitian ini adalah pendidikan kesehatan dengan media audio visual dan variabel terikatnya adalah pengetahuan remaja putri tentang SADARI. 
Penelitian ini menggunkan instrument kuesioner untuk pengumpulan data dimana kuesioner yang digunakan telah dilakukan uji valditas dan reabilitas sebelumnya. Prosedur pengumpulan data pada penelitian ini dimulai dengan pemilihan sampel. Setelah mendapatkan sampel sesuai kriteria inklusi dan eksklusi kemudian sampel dikumpulkan dan dilakukan pre test. Selesai melakukan pre test maka remaja putri akan mendapatkan pendidikan kesehatan. Pada minggu selanjutnya atau pertemuan kedua, siswi diberikan pendidikan kesehatan terlebih dahulu kemudian setelah itu barulah diberikan post test. Data yang didapatkan melalui pre test dan post test dibandingkan dan dilihat perbedaannya dengan menggunakan uji wilcoxon sign rank test dengan tingkat kepercayaan 95\% ( $\alpha$ : $0,05)$.

HASIL

\section{HASIL DAN PEMBAHASAN}

Tabel 1 Distribusi Frekuensi Responden Berdasarkan Umur Di SMAN 1 Kuta Utara

\begin{tabular}{ccc}
\hline Umur & Frekuensi & Presentase (\%) \\
\hline 14 tahun & 1 & 3 \\
\hline 15 tahun & 26 & 78,8 \\
\hline 16 tahun & 6 & 18,2 \\
\hline Total & 33 & 100 \\
\hline
\end{tabular}

Tabel 2 Distribusi Frekuensi Responden Berdasarkan Umur Menarche Di SMAN 1 Kuta Utara

\begin{tabular}{ccc}
\hline Umur & Frekuensi & Presentase (\%) \\
\hline 9 tahun & 3 & 9,1 \\
\hline 10 tahun & 5 & 15,2 \\
\hline 11 tahun & 25 & 75,8 \\
\hline Total & 33 & 100 \\
\hline
\end{tabular}

Tabel 3 Distribusi frekuensi responden berdasarkan pengetahuan siswi remaja putri sebelum diberikan pendidikan kesehatan dengan media audio visual

\begin{tabular}{ccc}
\hline $\begin{array}{c}\text { Pengetahuan } \\
\text { (Pre Test) }\end{array}$ & Frekuensi & $\begin{array}{c}\text { Presentase } \\
(\%)\end{array}$ \\
\hline Kurang & 17 & 51,5 \\
\hline Cukup & 16 & 48,5 \\
\hline Baik & 0 & 0 \\
\hline Total & 33 & 100 \\
\hline
\end{tabular}


Tabel 4 Distribusi frekuensi responden berdasarkan pengetahuan siswi remaja putri sesudah diberikan pendidikan kesehatan dengan media audio visual

\begin{tabular}{ccc}
\hline $\begin{array}{c}\text { Pengetahuan } \\
\text { (Post Test) }\end{array}$ & Frekuensi & $\begin{array}{c}\text { Presentase } \\
(\mathbf{\%})\end{array}$ \\
\hline Kurang & 0 & 0 \\
\hline Cukup & 13 & 39,4 \\
\hline Baik & 20 & 60,6 \\
\hline Total & 33 & 100 \\
\hline
\end{tabular}

Tabel 5 Analisis Pengaruh Pendidikan Kesehatan dengan Media Audio Visual Terhadap Pengetahuan Remaja Putri Tentang Pemeriksaan Payudara Sendiri (SADARI)

\begin{tabular}{lcc}
\hline $\begin{array}{l}\text { Perbedaan } \\
\text { tingkat } \\
\text { pengetahuan } \\
\text { pre test dan } \\
\text { post test }\end{array}$ & Jumlah & Asymp.Sig. \\
\hline Negatif ranks & 0 & \\
Positif ranks & 29 & 0,000 \\
Ties & 4 & \\
\hline Total & 33 & \\
\hline
\end{tabular}

\section{PEMBAHASAN}

Dari keseluruhan responden sebagian besar responden memiliki usia 15 tahun yaitu sebanyak $78,8 \%$ (26 orang responden) dan sebagian besar mengalami menarhe pada umur 11 tahun yaitu $75,8 \%$ (25 orang).

Berdasarkan data penelitian pemberian pendidikan kesehatan di SMAN 1 Kuta Utara didapatkan hasil pre test mayoritas responden berpengetahuan kurang yaitu sejumlah 17 orang $(51,5 \%)$ dari total responden 33 orang. Sedangkan berdasarkan data penelitian pemberian pendidikan kesehatan di SMAN 1 Kuta Utara didapatkan hasil post test mayoritas responden berpengetahuan baik yaitu sejumlah 20 orang $(60,6 \%)$ dari total responden 33 orang.

Hasil analisis data yang didapatkan menyatakan bahwa adanya perbedaan tingkat pengetahuan remaja putri sebelum diberikan pendidikan kesehatan dan setelah diberikan pendidikan kesehatan. Hal ini dapat dibuktikan dengan data yang didapatkan pada saat pre test, dimana siswi yang memiliki pengetahuan baik tidak ada, berpengetahuan cukup 16 orang, dan berpengetahuan kurang sebanyak 17 orang.

Pada saat post test atau setelah diberikan perlakuan hasil yang didapatkan siswi yang berpengetahuan baik berjumlah 20 orang, berpengetahuan cukup 13 orang, dan berpengetahuan kurang tidak ada. Berdasarkan hasil yang didapat menggunakan uji Wilcoxon Sign Rank Test diperoleh nilai sebesar $\mathrm{p}=0,000<\alpha$ $(\alpha=0,05)$ yang berarti Ho ditolak atau dapat disimpulkan bahwa ada pengaruh 
pendidikan kesehatan dengan media audio visual terhadap pengetahuan remaja putri tentang pemeriksaan payudara sendiri (SADARI). Hasil penelitian ini sejalan dengan teori yang dikemukakan oleh Mubarak (2011) yang menyatakan bahwa ada tujuh faktor yang mempengaruhi tingkat pengetahuan dan salah satunya adalah informasi. Penyampaian informasi dalam penelitian ini dilakukan melalui pendidikan kesehatan, dimana pendidikan kesehatan merupakan intervensi atau upaya yang ditujukan kepada masyarakat agar masyarakat mampu melakukan tindakan-tindakan yang mampu memelihara maupun meningkatkan kesehatan (Notoatmodjo, 2012).

Menurut Notoatmodjo (2011) pengetahuan merupakan hasil dari 'tahu' dan ini terjadi setelah orang melakukan penginderaan terhadap suatu objek. Penginderaan ini dapat dilakukan melalui media-media dalam penyampaian pendidikan kesehatan. Media yang digunakan dalam penelitian ini yaitu audio visual, dimana media audio visual merupakan media yang memiliki unsur suara dan unsur gambar dengan penyampaian melalui mesin mekanis atau elektronik. Penelitian ini didukung oleh Suastina (2013) dimana pada penelitian tersebut diperoleh data peningkatan pengetahuan yang terjadi sebelum diberikan perlakuan dan setelah diberikan perlakuan. Sebelum diberikan perlakuan, data pre test yang didapatkan yaitu 61 orang berpengetahuan kurang, sedangkan setelah diberikan perlakuan berupa pendidikan kesehatan didapatkan data post test yaitu 79 orang berpengetahuan baik dan hanya 6 orang yang berpengetahuan buruk. Hasil uji Wilcoxon Signed Rank Test didapatkan nilai sebesar $\mathrm{p}=0,000<\alpha(\alpha=0,05)$, yang berarti Ho ditolak atau dapat disimpulkan bahwa ada pengaruh pendidikan kesehatan terhadap tingkat pengetahuan siswi tentang SADARI sebagai deteksi dini kanker payudara di SMA Negeri 1 Manado.

Hasil penelitian ini juga sejalan dengan penelitian Mardiyana (2015) yang mengatakan ada pengaruh pendidikan kesehatan terhadap tingkat pengetahuan tentang pemeriksaan payudara sendiri (SADARI) pada remaja putri di Dusun Keret Desa Sumberjati, Mojoanyar Mojokerto. Kedua penelitian tersebut membuktikan bahwa ada pengaruh pendidikan kesehatan terhadap peningkatan pengetahuan. Menurut Sulistyowti (2016) pemberian pendidikan kesehatan berpengaruh pada pengetahuan siswi di SMK 1 Muhamadiyah Lamongan tentang bagaimana cara melakukan SADARI dengan benar. Menurut Suhita (2013) terdapat perbedaan yang signifikan antara pengetahuan remaja putri sebelum diberikan pendidikan kesehatan dan sesudah diberikan pendidikan kesehatan, dimana pengetahuan remaja putri stetelah diberikan pendidikan kesehatan mengalami peningkatan. Menurut Shorea (2014) pemberian pendidikan kesehatan dengan media audio visual sangat efektif dalam meningkatkan pengetahuan remaja putri tentang SADARI dilihat dari adanya peningkatan pengetahuan yang terjadi setelah remaja putri diberikan informasi melalui media audio visual.

\section{Simpulan}

\section{SIMPULAN DAN SARAN}

Berdasarkan hasil penelitian yang telah dilakukan, didapatkan bawah pada saat pre test mayoritas responden berpengetahuan kurang yaitu 17 orang, setelah diberikan pendidikan kesehatan didapatkan hasil post test bahwa responden mayoritas memiliki pengetahuan baik yaitu 20 orang. Menurut hasil tersebut 
didapatkan hasil analisis data yaitu $p$ value $=0,000$ atau $p$ value lebih kecil dibandingkan $\alpha(0,05)$ yang artinya terdapat pengaruh pendidikan kesehatan dengan media audio visual terhadap pengetahuan remaja putri tentang pemeriksaan payudara sendiri (SADARI) di SMAN 1 Kuta Utara.

\section{Saran}

Bagi remaja putri diharapkan kepada pihak sekolah agar ikut berperan dalam penyampaian informasi kesehatan kepada seluruh siswa / siswi guna meningkatkan pengetahuan siswa/siswi tentang kesehatan. Bagi pihak sekolah diharapkan kepada pihak sekolah agar ikut berperan dalam penyampaian informasi kesehatan kepada seluruh siswa / siswi guna meningkatkan pengetahuan siswa/siswi tentang kesehatan. Bagi peneliti selanjutnya diharapkan peneliti selanjutnya mampu meneliti faktor-faktor lain yang mempengaruhi pengetahuan remaja putri tentang pemeriksaan payudara sendiri (SADARI) contohnya pengalaman, kebudayaan, dan minat.Selain itu, diharapkan peneliti mampu melakukan pendidikan kesehatan dengan media ataupun metode yang berbeda.

\section{DAFTAR PUSTAKA}

American Cancer Society. (2016). Breast Cancer Facts and Figures. Retrieved February 19, 2018, from Anerican Cancer Society: https://www.cancer.org/content/dam/cancer-org/research/cancer-facts-andstatistics/breast-cancer-facts-and-figures/breast-cancer-facts-and-figures2015-2016.pdf

Dinas Kesehatan Badung. (2015, Mei 20). Program Inovasi Dinas Kesehatan. Retrieved April 14, 2018, from Dinas Kesehatan Pemerintahan Kabupaten Badung : http://dikes.badungkab.go.id/index.php/baca-berita/17/programinovasi-dinas-kesehatan-badung-:-tantangan-layanan-kesehatan-dan-hasil

Hidayati, A. (2013). Pengaruh Pendidikan Kesehatan Melalui Metode Ceramah dan Demonstrasi dalam Meningkatkan Pengetahuan Tentang Kanker Payudara dan Keterampilan Praktik SADARI. 1-8

Kusmiran, E. (2014). Kesehatan Reproduksi Remaja dan Wanita. Jakarta: Salemba Medika

Mardiyana, R. (2015). Pengaruh Pendidikan Kesehatan Terhadap Tingkat Pengetahuan Tentang Pemeriksaan Payudara Sendiri (SADARI) Pada Remaja Putri di Dusun Keret Desa Sumberjati, Mojoanyar Mojokerto. Jurnal Penelitian Kesehatan

Marmi. (2014). Kesehatan Reproduksi. Yogyakarta: Pustaka Pelajar

Shorea. (2014). Efektifitas Promosi Kesehatan Melalui Audio Visual Tentang Pemeriksaan Payudara Sendiri (Sadari) Terhadap Peningkatan Pengetahuan Remaja Putri. Universitas Riau, 1-2

Suastina, D. A. (2013). Pengaruh Pendidikan Kesehatan Terhadap Tingkat Pengetahuan Siswi Tentang SADARI Sebagai Deteksi Dini Kanker Payudara di SMA Negeri 1 Manado. ejournal keperawatan, 2

Sulistiyowati. (2016). Perilaku Sadari Remaja Putri Melalui Pendidikan Kesehatan di SMK 1 Muhammadiyah Lamongan. 2-3 
Yanti, E. D. (2015). Pengaruh Pendidikan Kesehatan dengan Menggunakan Media Audio Visual Terhadap Pengetahuan dan Sikap Remaja Mengenai Upaya Pencegahan Penyakit Menular Seksual. 1-8

Yayasan Kanker Indonesia. (2015). Retrieved February 20, 2018, from Yayasan Kanker Indonesia: http://yayasankankerindonesia.org 